\title{
Investigating the healing effect of the hydroalcoholic extract of pomegranate seed (Punica granatum) on the full thickness wound in rabbit
}

\author{
Ali Asghar Hemmati', Iran Rashidi², Sedigheh Dahanzadeh', Mahmoud Moeini
}

'Departmant of Pharmacology, School of Pharmacy, Ahvaz Jundishapur University of Medical Science, Ahvaz, Iran.

${ }^{2}$ Department of Pathology, School of Medicine, Ahvaz Jundishapur University of Medical Science, Ahvaz, Iran.

Corresponding Author: Sedigheh Dahanzadeh (E-mail:sedigheh.dahanzaadeh@yahoo.com)

(Submitted: 04 January 2020 - Revised version received: 12 February 2020 - Accepted: 17 February 2020 - Published online: 26 April 2020)

\begin{abstract}
Objective This research designed to investigate the wound healing process with pomegranate hydroalcoholic seed extract (Punica granatum) in comparison with no-treatment, betamethasone, phenytoin, and eucerin in rabbits.

Methods The positive group including groups that received phenytoin cream (1\%) and topical eucerin, respectively, twice a day to complete wound healing. negative control group did not obtain any treatment. Treatment groups were received cream of pomegranate seed extract (PSE) $(2,5,7,10 \mathrm{w} / \mathrm{w})$ in eucerin and $75 \% \mathrm{w} / \mathrm{w}$ as purified extract twice daily. In order to measure the percentage of wound healing, the zone of the wound was evaluated daily. Histological studies were done on the 7th and 15th days of treatment. Next, hydroxyproline content of wounds healed and tensile strength of wound tissue samples were measured.

Results The results demonstrated between PSE treatment groups and eucerin animals were statistically significant different $(P<0.05)$ in most of the days reviewed. Treatment of rabbits with 10\% PSE had the best results (complete wound recovery in 12 days). Also, this treatment showed higher hydroxyproline content and higher tissue strength.

Conclusion This research reveals that the extract of 10\% PSE administrated topically has the proper potential to induce wound recovery in the wound model of rabbits. In addition, 10\% PSE accelerates the healing of the wound. Further study needs to clarify the results of this research.

Keywords Pomegranate (Punica granatum), Hydroxyproline, Rabbit, Tensile strength, Wound healing
\end{abstract}

\section{Introduction}

The skin is an organ that covers the external surface of the body and protects it from exterior hazards. This organ includes the skin and its derivatives such as skin glands (oil glands and sweat glands), hair, nails, and breast. Anatomically, from exterior to interior the skin includes three layers which are called: epidermis, dermis, and hypodermis (or the subcutaneous oil tissues).

The wound is defined as tissue rupture and/or local destruction of epidermis and dermis which eventually results in the remaining scar. Healing includes two steps: (1) contraction and (2) replacement of the destroyed tissue which occurs via cell transfer and division of alongside cells. ${ }^{2,3}$

First, a temporary arteriole contraction occurs and afterward the vessels dilate. Neutrophils initiate adhesion to blood vessel walls and vessel permeability increases. Leukocytes and few lymphocytes appear and glycoprotein networks surround them during the first $3 \mathrm{~h} .{ }^{4-6}$

The number of neutrophils in wound increases during the first $48 \mathrm{~h}$. Few monocytes appear in the first $24 \mathrm{~h}$, and then increase in the following days. Macrophages increase gradually along with neutrophil number reduction. Macrophages produce fibroblast growth factors as well as factors responsible for new vessel production. Blood coagulation is the first healing signal.

Fibrinopeptide and thrombin attract the macrophages to the damaged tissue and the activated platelets secrete PDGF, IGF-1, and TGF $\beta$ which all prepare the target cells for proliferation. Subsequently, fibrin stimulates the macrophages to secrete more healing signals. ${ }^{8}$ When damaged endothelial cells secrete cytokines, integrin and its receptor appear on the surface of passing leukocytes and inflammation begins Newcomer inflammatory cells increase the metabolic need. ${ }^{9}$
Since the local microvascular construction is damaged, energy and $\mathrm{O}_{2}$ reduction, and $\mathrm{CO}_{2}$ and lactate accumulation occur at the damaged site. These happenings initiate the healing process and reassure its maintenance. ${ }^{10}$

In wounds that are initially sewed, the branched vessels quickly join the branched vessel from the front and the blood circulation of the wound is established. ${ }^{12}$ In remaining or not fully closed wounds, the new vessels only join the neighbor vessels on the same side of the wound and the granulation tissue is created instead. ${ }^{13}$

Angiogenesis is inducible by the addition of chemotactic substances to the endothelial cells in the tissue body of the wound. It seems that wound angiogenesis is a response to local energy reduction and its general mechanism is very similar to the mechanism of collagen sediment regulation. ${ }^{11}$ In unsuitable conditions (hypoxia or lactate increasing), macrophages secrete a chemotactic peptide for endothelial cells which leads to angiogenesis. ${ }^{14}$

$\mathrm{NAD}+$ reserve protection inhibits this process drastically. Therefore, the unanswered metabolic needs cause an anatomical response with means of a series of growth factors that probably have high importance. ${ }^{15}$

This step starts approximately from Day 4 or 5 . During healing, fibroplasia (fibroblast proliferation) is stimulated from various mechanisms that start with secretion of PDFG, IGF-1, and TGF $\beta$ from platelets and resumes with the secretion of cytokines from the macrophage. ${ }^{16}$

Fibroblasts secrete IGF-1. Epidermal growth and GF1 are also transferred to the damage site via blood circulation. Healing fibroblasts are mostly seen near the wound edges. ${ }^{17}$ At this place, an appropriate growth environment and oxygen pressure close to $40 \mathrm{mmHg}$ are available for them in normal wounds. ${ }^{18}$ 
This oxygen pressure is optimal for fibroblast proliferation in cell culture. From the newly proliferated fibroblasts, collagen and proteoglycan are secreted which brings close the wound edges. ${ }^{19}$

Both substances are in polymeric form with large molecules which bases the physical strength of the wound. Collagen synthesis is not specifically limited to fibroblasts but is regulated gravely via these cells. ${ }^{20}$

Some growth factors (IGF-1, TGF $\beta$ ) cause transcription of the collagen gene. Evidence shows the increase of collagen mRNA results in the increase of procollagen peptide but this is not enough to raise the amount of collagen sediment, since procollagen peptide cannot transfer to the extracellular environment without the hydroxylation of some of its proline agents. $^{21}$

Epithelial cells respond to many fibroblasts and endothelial stimuli. In the healing process, epithelium mitosis happens a few cells farther from the edge of the wound. New cells travel from the edge of the wound to the unhealed area and probably adhere to the first non-epithelized area by a growth factor or cytokine and form the new edge of the wound. ${ }^{22}$

Oxygen pressure is probably low in the cellular joint. This low $\mathrm{O}_{2}$ pressure stimulates TGF $\beta$ production from the squamous epithelial, inhibits the final dissociation, and increases mitosis. This process continues until the wound closes. ${ }^{23}$

Squamous epithelization and dissociation continues at maximum as long as $\mathrm{O}_{2}$ pressure reaches $70 \mathrm{mmHg}$ and the wound surface remains moist. Opposed to the classical theory, even short periods of wound drying can disturb this process. $^{24}$

The exodus of acute, non-infectious, and surface wound also contains growth factor and lactate, therefore, accommodates the growth environment within. The second to the third level of the healing process progresses gradually. The extracellular matrix turnover is a complex process. First fibroblasts replace the initial fibrin matrix with collagen monomers. ${ }^{25}$

Extracellular enzymes (which some of them depend on oxygen pressure) polymerize these monomers quickly. ${ }^{26}$ This polymerization has a more disordered nature compared to normal situation, and therefore new wounds are weak and fragile. When this initial matrix is replaced by a more mature kind which includes bigger, stronger, more ordered, and more persistent fibers, the wounded delicacy is hindered. ${ }^{27}$

Turnover and reorganization of the new matrix are very important in the healing process. Fibroblasts and leukocytes lyse the matrix with the secretion of collagenase. Replacement of the old matrix with a new matrix takes place first quickly, and then gradually. ${ }^{28}$

Pomegranate is a small family including a genus, containing two species with characteristics similar to the Myrtaceae family. Pomegranate has a rugged stem with hardwood and covered with a somewhat green color. Its multiple branches have irregular shapes and special colors and usually have sharp thorn-like ends. ${ }^{29,30}$

Simple dark and usually reciprocal leaves and malefemale flowers are among its characteristics. Their calyx contains 4-8 flesh-like pieces and is joined to the pod. Pomegranate fruit is a sphere as big as an orange and sometimes larger, with relatively thick and red, soft and uneven skin, soft, and uneven. ${ }^{31}$

Some pomegranate breeds have yellowish-white skin. The seeds inside the fruit are surrounded in pink flesh-like covers and its flower is scentless. This plant is dispersed mostly in Europe, North Africa, Asia, and Iran. In traditional medicine of Iran, all parts of the pomegranate plant are used. ${ }^{32}$

Different parts of pomegranate especially the root skin and stem have $22 \%$ tannic acid and picotannic acid, pyrogallic acid, gratanotannic acid, resin, and mucilage. It also contains alkaloids such as pelletierine, iso pelletierine, methyl pelletierine, and pseudo-pelletierine. In addition, many others exist in pomegranate fruit such as vitamins B1, B2, B6, C, and minerals such as potassium, phosphorus, iron, and sodium. ${ }^{33}$

\section{Materials and Methods}

\section{Plant Material}

Pomegranate fruits were collected in December from the surrounding gardens of Isfahan and then seeds were manually separated and dried in the shade for 1 week. To prepare the pomegranate extract, soaking method with ethanol (70\%) solvent was used. $500 \mathrm{~g}$ of powdered seeds were poured into the beaker and $5 \mathrm{ml}$ of solvent per gram of powder was added. Soaking was performed for $72 \mathrm{~h}$. Every $12 \mathrm{~h}$, the mixture was stirred while soaking. After $72 \mathrm{~h}$, the mixture was filtered with a clean cloth, and then through filter paper and a Buchner funnel. Afterwards, extract concentration was performed with the rotary machine at a temperature of $65^{\circ} \mathrm{C}$ for $70 \mathrm{~h}$. Extract obtained per $50 \mathrm{~g}$ of powdered pomegranate seeds was $9.4 \mathrm{~g}$ and the amount of resulting extract was calculated as $15.8 \%$.

\section{Animals}

Experiment animals, male and female Iranian rabbits were prepared from the animal care center with weight range of 1.2-1.8. They were kept in the School of Pharmacy animal room in individual aluminum cages with conditions of $12 \mathrm{~h}$ light, $12 \mathrm{~h}$ dark, and temperatures of $2 \pm 22^{\circ} \mathrm{C}$. Compact food, carrots, lettuce, and water were available for the animals without limitation.

\section{Wound Creation}

The place of the wound is on the side of the animal near the spine. For wounding, according to Hemmati \& Mohammadian method, first the hair of wound area was removed using shaving machine and blade and thoroughly cleaned. Then local anesthesia was created using lidocaine. Animal was placed in Standard Crouching Position. The moving skin was kept with fingers and using a shablon and pen, a $20 \times 20 \mathrm{~mm}$ square was drawn on the skin. Thereafter, layers of the epidermis, dermis, and hypodermis of animal skin were fully removed by No. 15 scalpel, forceps, and surgical scissors. After wounding, the wound was rinsed with saline, the wound surface was measured and animals were returned to their separate cages. After $24 \mathrm{~h}$, daily measuring of wounds began. To measure, the animal was placed in the standard crouching position, then using a transparent the sides of the wound (wound area) were plotted and its area was measured using graph paper, because this study is basically to compare the level of residual wound. To minimize errors of observation, the animal was placed in standard position and each wound surface was plotted three times. The coagulation on the wound surface should never be physically moved, because it certainly causes an impact to the wound and the wound bed, thus prevents the favorable report of the wound. 


\section{Groups Studied}

1 - Wound group with no treatment. (Control group)

2 - Wound group receiving $1 \%$ phenytoin on the wound. (Positive control, because this drug is a standard wound healer)

3 - Wound group with Eucerin ointment base rubbed on their wounds. (As negative control)

4 - Wound group receiving 2\% extract in Eucerin base on the wound

5 - Wound group receiving 5\% extract in Eucerin base on the wound

6 - Wound group receiving 10\% extract in Eucerin base on the wound

7 - Wound group receiving the purified extract (75\%) in order to observe the effect of purified extract in wound healing and the amount of purified extract was equivalent to other groups.

8 - Wound group receiving betamethasone $0.1 \%$ ointment on the wound.

\section{Pathological Study}

A skin sample was prepared on the 7th day from each group for pathological and histological studies. Using forceps, scalpel, and surgical scissors, the wound area and some of the healthy skin surrounding it was removed and then immediately transferred to the container with formalin buffer $10 \%$. Sections with thickness of $5 \mu \mathrm{m}$ were prepared and stained with hematoxylin and eosin, and then were examined by light microscopy.

\section{Determination of Hydroxyproline and Collagen in Skin Samples}

The amount of hydroxyproline in skin samples is measured using Obrien et al (1965) method by spectrophotometer. The total amount of collagen is calculated presuming $12.5 \%$ of it comprises hydroxyproline. Hydroxyproline is separated from collagen by acid hydrolysis and is oxidized to Pyrole using Chloramine-T solution and produced a red color using Paradimethyl amino benzaldehyde (Erlich reagent).

\section{Measuring the Elasticity of the Skin Samples}

After treatment period, skin strips with dimensions of $20 \times 5$ $\mathrm{mm}$ were isolated from the wound and placed under tension. Two ends of tissue were attached to special and then a gradual stretching was applied to the tissue until it was torn. The amount of resistance in wounded tissues in different groups and healthy skin were compared.

\section{Ethical Considerations}

Due to work on animals using standard methods with consideration of ethics and anesthesia induction when wounding and using sterile pharmaceutical products, moral principles related to the work on experiment animals were precisely observed.

\section{Data Analysis}

Data obtained during the treatment consisted of the amount of hydroxyproline and quantitative tissue resistance. Using ANOVA different groups were statistically compared.

\section{The Results of Wound Healing}

\section{Comparison of the Wound Healing in Untreatment, Eucerin- and Phenytoin-Treated Groups}

In Eucerin-treated rabbits group, treatment took 21 days and the percentage of wound healing from macroscopic view reached $100 \%$. Statistical tests revealed it doesn't have a significant difference compared to $2 \%$ group $(P>0 / 05)$. Compared to $5 \%$, it is significantly different except on days $6,11,12,13$, and 16. Compared to $10 \%$, it has significant difference on all days except the first. Compared to $75 \%$, it is significantly different on all days except $6,11,12,15$, and 16. Compared to phenytoin-treated group, it was significantly different on all days except 2, 3, 4, and 7 ( $P<0 / 05$; Fig. 1$)$.

\section{Comparison of Average Hydroxyproline Amount in Different Groups on the Last Day of Treatment}

The aim of study was measuring the amount of hydroxyproline in each treatment groups and comparing the hydroxyproline levels in different groups. The results show that phenytoin-treated group and the group treated with $10 \%$ pomegranate seed extract have the highest concentration of hydroxyproline (micrograms per gram), where no treatment group and eucerin-treated group had the lowest amount and hydroxyproline in treatment groups with $2 \%, 5 \%$, and $75 \%$ of pomegranate seed extract and betamethasone ranged between the minimum and maximum concentrations. The results of statistical tests to compare the hydroxyproline amount in different groups shows that the $10 \%$ group and the phenytoin-treated group have significant difference with each other and with all other groups $(P<0 / 05) .2 \%, 5 \%$, and $75 \%$ and betamethasone groups have no significant difference with each other $(P<0 / 05)$

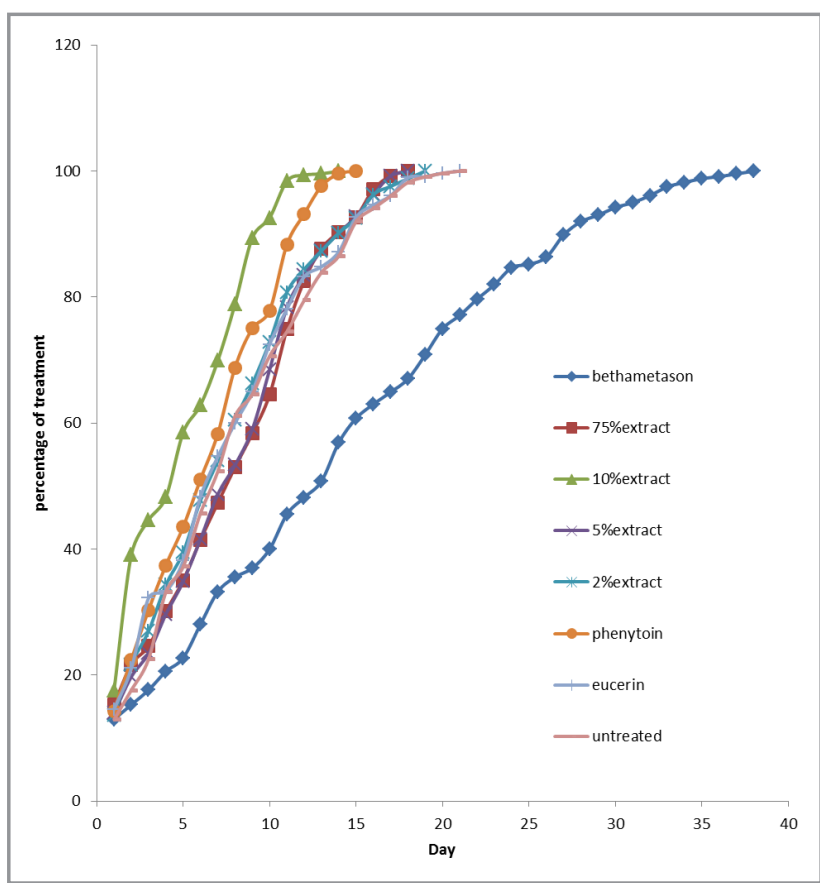

Fig. 1 Comparison of the wound healing in untreatment eucerin- and phenytoin-treated groups. Data are expressed as (mean \pm SEM). Values significantly different from eucerin-treated or no-treatment are indicated as * $(P<0 \cdot 01)$. 


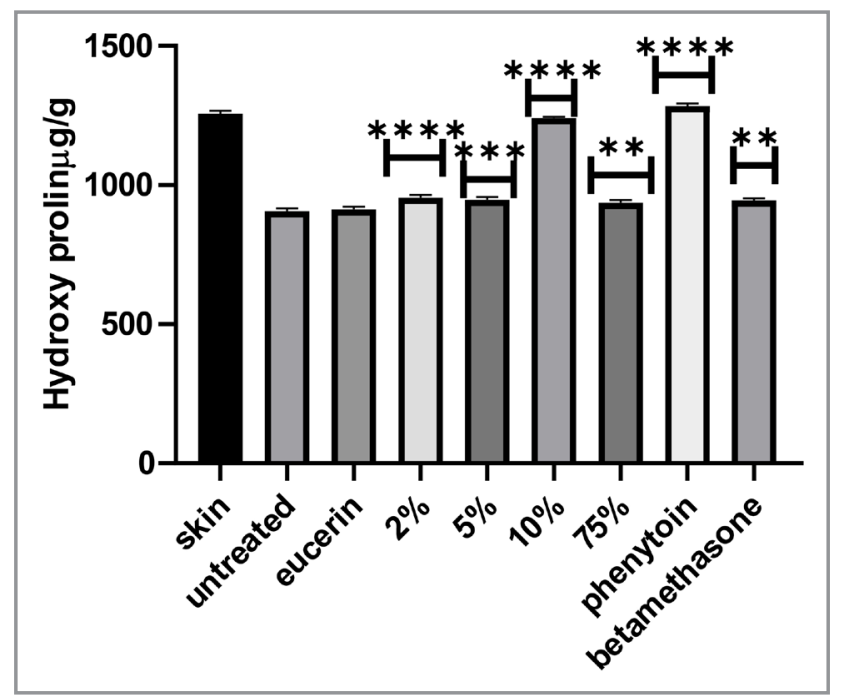

Fig. 2 Comparative graph of hydroxyproline $(\mu \mathrm{g} / \mathrm{g})$ in treated and untreated groups on the last day of treatment. Data are expressed as (mean \pm SEM). Values significantly different from eucerintreated or no-treatment are indicated as $*(P<0 \cdot 01)$.

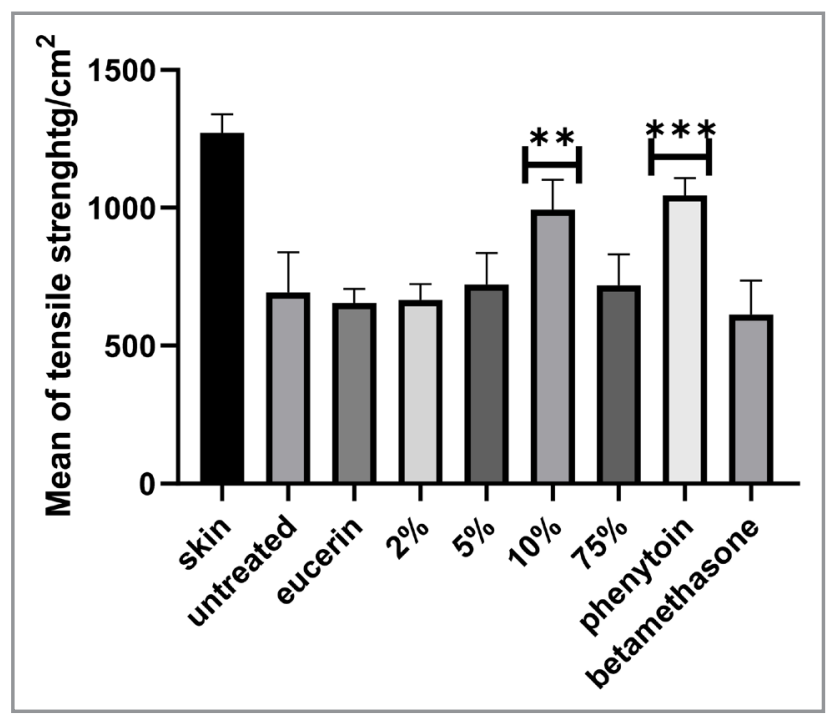

Fig. 3 Comparison of mean tissue resistance to stretch in all treated groups plus untreated and betamethasone on the last day of treatment. Data are expressed as (mean \pm SEM). Values significantly different from eucerin-treated or no-treatment are indicated as $*(P<0.01)$.

but are significantly different compared with other groups. No treatment group and eucerin-treated group also do not have a significant difference with each other but compared to other groups are significantly different $(P<0 / 05$; Fig. 2$)$.

\section{Comparison of Average Tissue Resistance Against Stretching in All Treatment Groups with No Treatment Group and Betamethasone on the Last Day of Treatment}

The aim of this study was to measure and compare the average resistance of healed tissue to stretch. The results showed that the group treated with the $10 \%$ extract and phenytoin (10\%) had the highest resistance to stretching compared with other groups which was significantly different $(P<0 / 05)$.

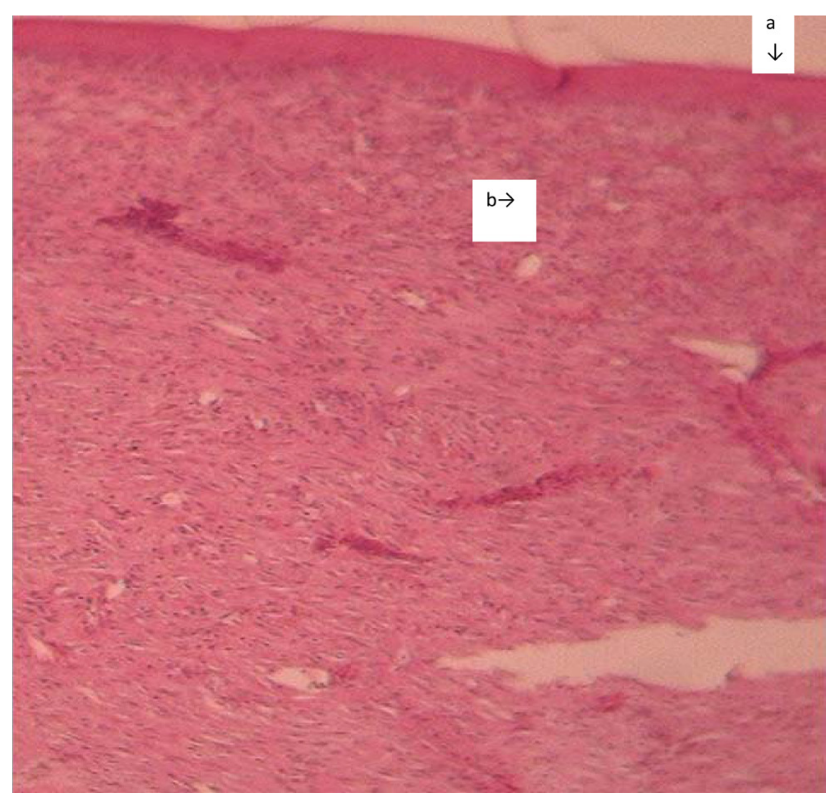

Photomicrograph of tissue specimens of rabbits treated with $2 \%$ pomegranate seed extract at the end of treatment, formed (a) thin epidermis and granulation in the dermis (b), few inflammatory cells

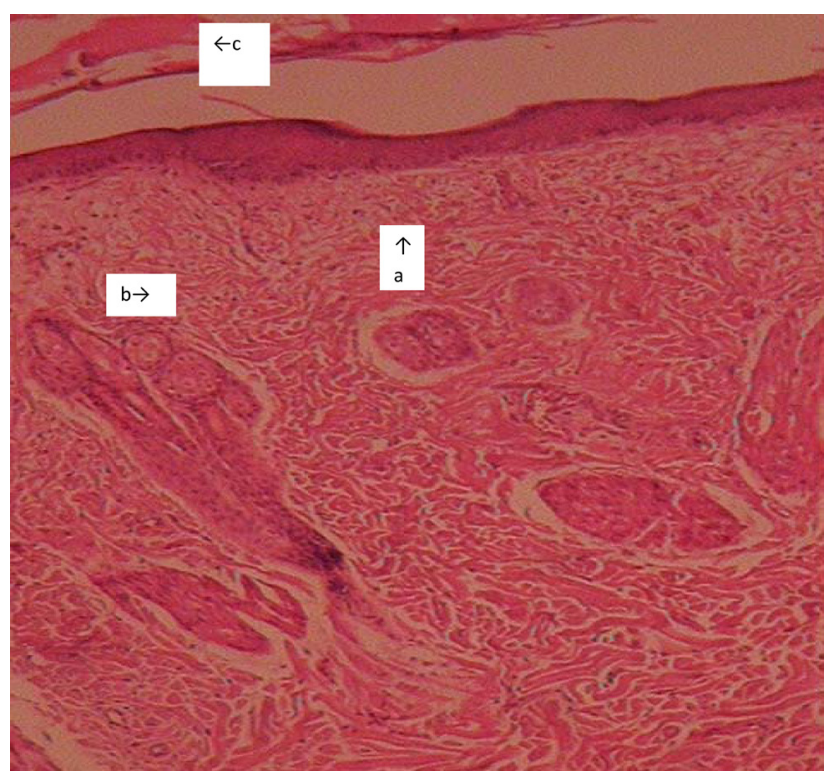

Photomicrograph of rabbit tissue specimen treated with $5 \%$ pomegranate seed extract at the end of treatment at epidermis: (a) with relatively good thickness and in dermis, (b) granulation tissue with collagen deposited repaired, (c) wound scab has been seen.

Betamethasone group had the least resistance. Eucerin, no treatment, $2 \%, 5 \%$, and $75 \%$ groups had the resistance value ranging between the lowest and highest amount and were significantly different with these groups $(P<0 / 05$ : Fig. 3$)$.

\section{Discussion}

Given that the wound healing process has many complications, therefore, this seems necessary to know topical drugs for wounds that have the greatest effect on wound healing. In this research, the most aim is the comparison of average wound healing in different groups treated with various concentrations 


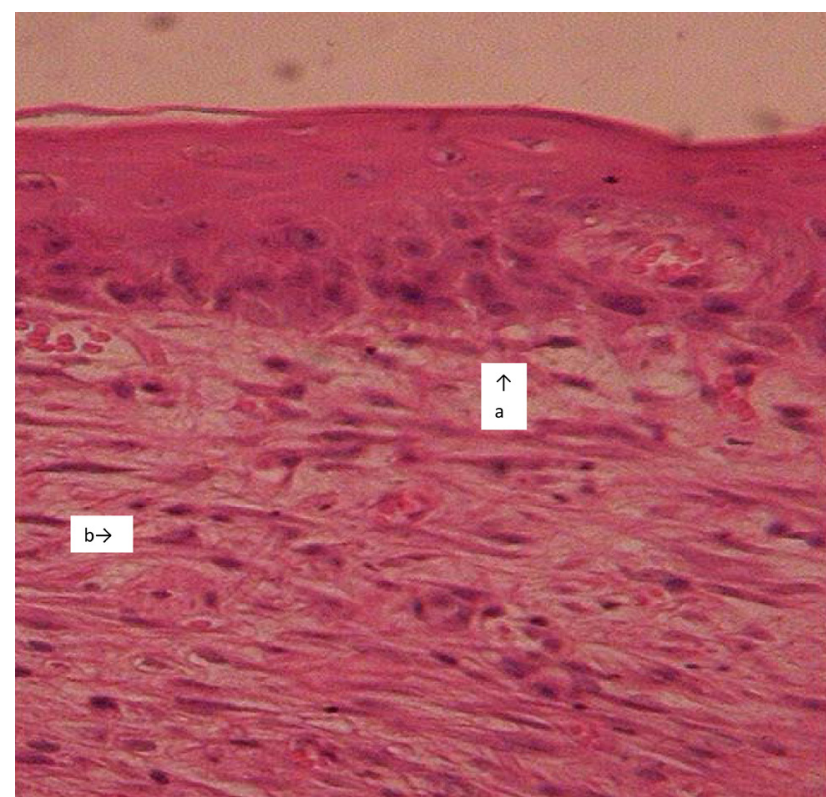

Photomicrograph of rabbit tissue section treated with $10 \%$ pomegranate seed extract on the end of epidermal treatment day: (a) thickly formed, (b) fibroblasts stretched, collagen density high, not edema, and inflammatory cells. In this image, fibroblasts have been found to be elongated ( $400-H \& E^{*}$ )

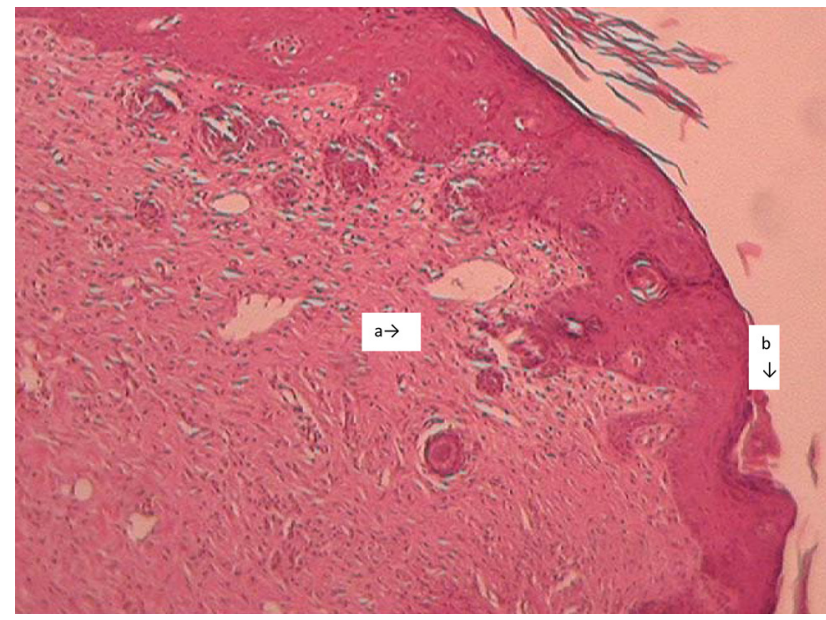

Photomicrograph of rabbit tissue section treated with eucerin on the end of epidermal treatment day in epidermis area. (a) Inflammatory cell aggregation is seen, germ cell migration is clear, (b) wound scab has been seen (400 - H\&E*).

of the pomegranate (Punica granatum) seed extract (PSE) in comparison to phenytoin and betamethasone.

In this study, phenytoin $1 \%$ as control positive and $10 \%$ PSE can create the optimum result of formation hydroxyproline, whereas eucerin and no treatment groups have a low effect on hydroxyproline constitution in wound healing.

Phenytoin cream, while being effective, causes some systemic side effects that contain neutropenia, erythema multiform, crystalluria, and hydroxyproline production. ${ }^{34}$ In the other hand, prolonged and excessive hydroxyproline formation process causes the risk of delayed wound healing. ${ }^{35}$

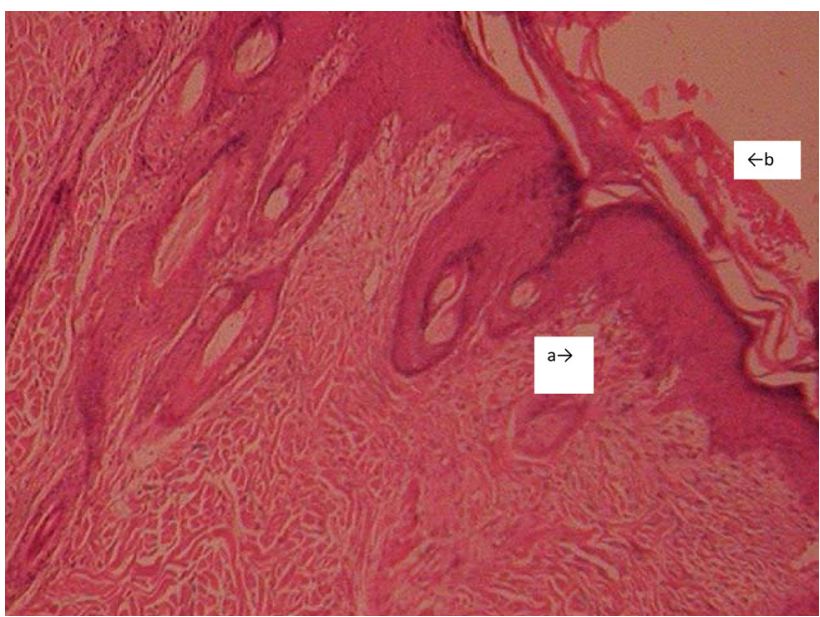

Photomicrograph of rabbit tissue section treated with $75 \%$ pomegranate seed extract on the end of epidermal treatment day: (a) tinny epidermis formed not fully fibroblasts stretched, collagen density high, low inflammatory cells and (b) wound scab has been seen. $\left(400-H \& E^{*}\right)$

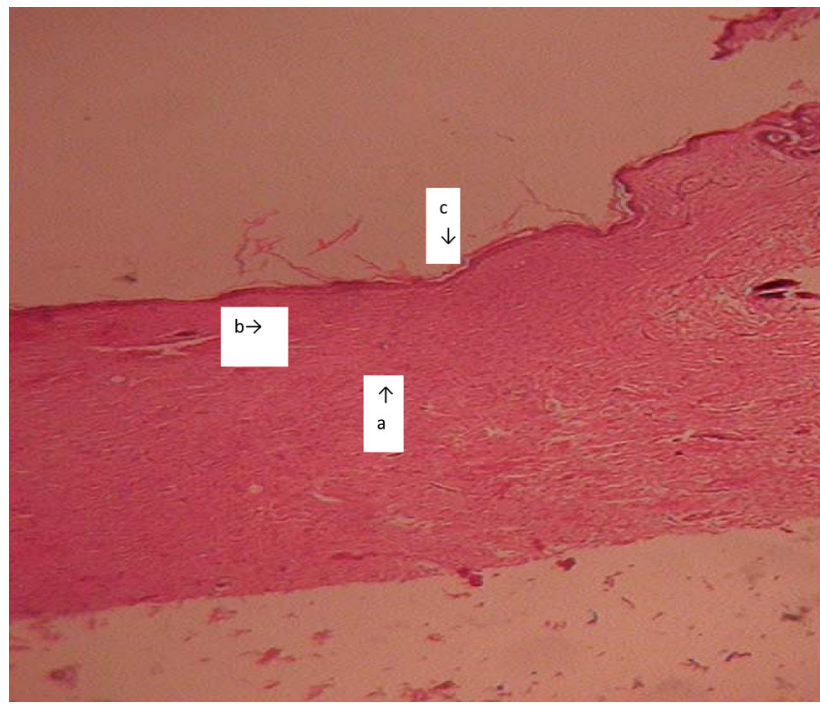

Photomicrograph of rabbit tissue section treated with phenytoin on the end of epidermal treatment day. (a) Tinny epidermis and granulation tissue have formed in dermis, (b) wound scab has been seen (100 - H\&E*).

A healing tissue synthesizes collagen, which is a constituent of the growing cells. The amount of hydroxyproline is a scale of concentration of collagen. Collagen synthesis is a complex construction coordinator of intracellular and extracellular cell growth and repair. ${ }^{36}$

In addition to the synthesis of the polypeptide chains more than modifications of the molecule occur; most of these are enzymatic and specific for collagen. Hydroxyproline as measuring factor of collagen is an essential component of the skin repair and utilized as an adjunctive wound healing therapy stimulates and recruits immune cells and fibroblasts, 
thereby preserving native ECM structure and promoting healing. ${ }^{37}$

Fibrocytes are one of the most important cells producing cytokines such as (TGF- $\beta 1$ and TNF- $\alpha$ ) involved in the synthesis of collagen during both the inflammatory and the repair phase of the wound healing response. ${ }^{38}$

Commonly, pomegranate has various active substances that can act as an antibacterial, anti-inflammatory, and strong antioxidants. Pomegranate including tannin, flavonoid, punicic acid, and phytoestrogen. ${ }^{39}$

Little research has been done in the field extract of pomegranate effect on wound healing the evidence has shown pomegranates protect and strengthen skin cells on the surface and regenerate cells in the deeper layers of skin. ${ }^{40}$

Many substances such as ellagic acid and standardization in pomegranate can strengthen the pharmacologic effect of this fruit as a topical drug. ${ }^{41}$

Chinese and Indian complementary medicine use natural herbal materials because herbal medicine has advantages over modern medicine. ${ }^{42}$ The various active substances of herbal drugs can expand the pharmaceutical spectrum and increased positive results of treatment. These important roles are mainly linked to the mechanism of the body involved in organs and cells in the accountability to repair any disturbance in the body. ${ }^{43}$

The perturbation creates a lack of balance in the body. All the organs and cells of the body are involved in returning to balance. It is noted that various active components of the herbal material can improve the injuries of organs and tissue and cells which single drugs cannot. In the latest study, pomegranate can be used as antibacterial agents. ${ }^{44}$

In the inflammation phase, many chemical mediators cause the expression of cyclooxygenase- 2 which induced prostaglandins synthesis. ${ }^{45}$

Also, pomegranate has antioxidant properties that can prevent the oxidative stress via sustaining expression level of malondialdehyde, glutathione, glutathione peroxidase, and catalase $^{46}$

In this research, the result of skin collagen formation can be related to an optimal healing stage of rat wound. $10 \%$ extract of pomegranate seed similar phenytoin shows significant results of collagen formation in wound. From these findings, it is understood that using $10 \%$ extract of pomegranate likely promotes a synergic mechanism to provide an optimal process of rat wound healing. The current research shows that topical application of $10 \%$ extract of pomegranate represents a proper approach to improve dermal wound. It is noted, according to our previous researches on herbal extracts, we survey 2, 5, 10, 75 extract concentration on wound healing that result shows $10 \%$ extract had the most effective wound healing in terms of skin hydroyprolin and tissue resistance against stretching in comparison to other concentration. Also, topical $10 \%$ extract similar phenytoin shows markedly promotion and improve wound in reducing period of healing from 20 days (for no-treatment or eucerin-treated) to 12 days. The time period results of various concentration of extract were reproducible because they tested in a group of at least six rats. The macroscopic research of $10 \%$ extract group was consistent with results from hydroxyproline measure or tensile strength values. $10 \%$ extract was almost equal potent with phenytoin.

\section{Funding Information}

Ahvaz Jundishapur University of Medical Science, Grand/ Award Numbers:PRC-80.

\section{Conflict of Intrest}

The authors declare no conflicts of interest.

\section{Acknowledgment}

The present study was supported by Ahvaz Jundishapur University of Medical Sciences (Project grant: PRC-80), Ahvaz, Iran.

\section{References}

1. Rawlings AV. Ethnic skin types: are there differences in skin structure and function? Int J Cosmetic Sci. 2006;28(2):79-93.

2. Rodero MP, Khosrotehrani K. Skin wound healing modulation by macrophages. Int J Clin Exp Pathol. 2010;3(7):643.

3. Dorsett-Martin WA. Rat models of skin wound healing: a review. Wound Repair Regen. 2004;12(6):591-9.

4. Wilgus TA. Immune cells in the healing skin wound: Influential players at each stage of repair. Pharmacol Res. 2008;58(2):112-6.

5. Martin C, Muir I. The role of lymphocytes in wound healing. Br J Plast Surg. 1990;43(6):655-62

6. Peterson JM, Barbul A, Breslin RJ, Wasserkrug HL, Efron G. Significance of T-lymphocytes in wound healing. Surgery. 1987;102(2):300-5.

7. Koh TJ, DiPietro LA. Inflammation and wound healing: The role of the macrophage. Expert Rev Mol Med. 2011;13.

8. Wolberg AS. Thrombin generation and fibrin clot structure. Blood Rev. 2007;21(3):131-42.

9. Hertle MD, Kubler M-D, Leigh IM, Watt F. Aberrant integrin expression during epidermal wound healing and in psoriatic epidermis. J Clin Investig. 1992;89(6):1892-901.

10. Waris TH, Kaarela OI, Raatikainen TK, Teerikangas HE, Heikkinen ES. Microvascular flaps from the lateral arm and radial forearm for the repair of defects of the Achilles tendon region. Scand J Plast Reconst Surg Hand Surg. 1991;25(1):87-9.

11. Lee PC, Salyapongse AN, Bragdon GA, Shears LL, Watkins SC, Edington HD, et al. Impaired wound healing and angiogenesis in eNOS-deficient mice. Am J Physiol-Heart Circul Physiol. 1999;277(4):H1600-H8.

12. Dietze G, Wicklmayr M. Pharmaceutical composition and method of stimulating blood circulation and wound healing. Google Patents; 1979

13. Schindl A, Schindl M, Schön H, Knobler R, Havelec L, Schindl L. Lowintensity laser irradiation improves skin circulation in patients with diabetic microangiopathy. Diab Care. 1998:21(4):580-4.

14. Modarressi A, Pietramaggiori G, Godbout C, Vigato E, Pittet B, Hinz B. Hypoxia impairs skin myofibroblast differentiation and function. J Investig Dermatol. 2010;130(12):2818-27.

15. Hawrylyshyn KM. Nicotinamide Riboside Delivery Generates NAD+ Reserves to Protect Vascular Cells Against Oxidative Damage. 2015.

16. Clark RA. Regulation of fibroplasia in cutaneous wound repair. Am J Med Sci. 1993;306(1):42-8

17. Lewis DA, Travers JB, Somani A-K, Spandau DF. The IGF-1/IGF-1R signaling axis in the skin: a new role for the dermis in aging-associated skin cancer. Oncogene. 2010;29(10):1475-85.

18. Moulin V. Growth factors in skin wound healing. Eur J Cell Biol. 1995:68(1):1-7.

19. Hehenberger K, Brismar K, Lind F, Kratz G. Dose-dependent hyperbaric oxygen stimulation of human fibroblast proliferation. Wound Repair Regen. 1997;5(2):147-50

20. Jimenez S, Freundlich B, Rosenbloom J. Selective inhibition of human diploid fibroblast collagen synthesis by interferons. J Clin Investig. 1984;74(3):1112-6.

21. Hung CF, Rohani MG, Lee S-S, Chen P, Schnapp LM. Role of IGF-1 pathway in lung fibroblast activation. Respir Res. 2013;14(1):102.

22. Delavary BM, van der Veer WM, van Egmond M, Niessen FB, Beelen RH. Macrophages in skin injury and repair. Immunobiology. 2011;216(7):753-62. 
23. Scheid A, Wenger R, Christina H, Camenisch I, Ferenc A, Stauffer U, et al. Hypoxia-regulated gene expression in fetal wound regeneration and adult wound repair. Pediatr Surg Int. 2000;16(4):232-6.

24. Mortazavi R, Chitte S, Philip A. 154 Regulation of TGF- $\beta$ and its signaling components by oxygen tension and steroids in skin cells. Wound Repair Regen. 2005;13(2):A28-A48.

25. Toy L. Matrix metalloproteinases: Their function in tissue repair. J Wound Care. 2005;14(1):20-2.

26. Rousselle P, Montmasson M, Garnier C. Extracellular matrix contribution to skin wound re-epithelialization. Matrix Biol. 2019;75:12-26.

27. Kähäri VM, Saarialho-Kere U. Matrix metalloproteinases in skin. Exp Dermatol. 1997;6(5):199-213.

28. Rittié L. Cellular mechanisms of skin repair in humans and other mammals. J Cell Commun Signal. 2016;10(2):103-20.

29. Huan Y, Peng K-j, Wang Q-I, Gu Z-y, Lu Y-q, Jun Z, et al. Effect of pomegranate peel polyphenol gel on cutaneous wound healing in alloxaninduced diabetic rats. Chin Med J. 2013;126(9):1700-6.

30. Mo J, Panichayupakaranant P, Kaewnopparat N, Nitiruangjaras A, Reanmongkol W. Wound healing activities of standardized pomegranate rind extract and its major antioxidant ellagic acid in rat dermal wounds. J Nat Med. 2014;68(2):377-86.

31. Holland D, Hatib K, Bar-Ya'akov I. Pomegranate: Botany, horticulture, breeding. Horticult Rev. 2009;35(2):127-91.

32. Chandra R, Babu KD, Jadhav VT, Jaime A, Silva T. Origin, history and domestication of pomegranate. Fruit Vegetab Cereal Sci Biotechnol. 2010;2:1-6.

33. Bedigian D. Pomegranates. Ancient roots to modern medicine. Medicinal and aromatic plants_-Industrial profiles 43. Econ Bot. 2007;61(1):107-8.

34. Bhatia A, Prakash S. Topical phenytoin for wound healing. Dermatol Online J. 2004;10(1)

35. Park JE, Abrams MJ, Efron PA, Barbul A. Excessive nitric oxide impairs wound collagen accumulation. J Surg Res. 2013;183(1):487-92.
36. Portera CA, Love EJ, Memore L, Zhang L, Mueller A, Browder W, et al. Effect of macrophage stimulation on collagen biosynthesis in the healing wound. Am Surg. 1997;63(2):125-31.

37. Ågren M, Jorgensen I, Andersen M, Viljanto J, Gottrup P. Matrix metalloproteinase 9 level predicts optimal collagen deposition during early wound repair in humans. Br J Surg. 1998:85(1):68-71.

38. Spelman K, Burns J, Nichols D, Winters N, Ottersberg S, Tenborg M. Modulation of cytokine expression by traditional medicines: a review of herbal immunomodulators. Altern Med Rev. 2006:11(2):128.

39. De Jesus NZT, Falcão HdS, Gomes IF, Leite TJdA, Lima GRdM, Barbosa-Filho JM, et al. Tannins, peptic ulcers and related mechanisms. Int J Mol Sci. 2012;13(3):3203-28.

40. Jurenka J. Therapeutic applications of pomegranate (Punica granatum L.): A review. Altern Med Rev. 2008;13(2).

41. Yoshimura M, Watanabe Y, Kasai K, Yamakoshi J, Koga T. Inhibitory effect of an ellagic acid-rich pomegranate extract on tyrosinase activity and ultraviolet-induced pigmentation. Biosci Biotechnol Biochem. 2005:69(12):2368-73

42. Patwardhan B. Bridging Ayurveda with evidence-based scientific approaches in medicine. EPMA J. 2014:5(1):19.

43. Karimi A, Majlesi M, Rafieian-Kopaei M. Herbal versus synthetic drugs; beliefs and facts. J Nephropharmacol. 2015:4(1):27-30.

44. Kim HG, Kim JM, Han JM, Lee JS, Choi MK, Lee DS, et al. Chunggan extract, a traditional herbal formula, ameliorated alcohol-induced hepatic injury in rat model. World J Gastroenterol. 2014;20(42):15703-14.

45. Afaq F, Saleem M, Krueger CG, Reed JD, Mukhtar H. Anthocyanin- and hydrolyzable tannin-rich pomegranate fruit extract modulates MAPK and NF-kappaB pathways and inhibits skin tumorigenesis in CD-1 mice. Int J Cancer. 2005:113(3):423-33.

46. Wu Y, Zhu CP, Zhang Y, Li Y, Sun JR. Immunomodulatory and antioxidant effects of pomegranate peel polysaccharides on immunosuppressed mice. Int J Biol Macromol. 2019;137:504-11.

This work is licensed under a Creative Commons Attribution-NonCommercial 3.0 Unported License which allows users to read, copy, distribute and make derivative works for non-commercial purposes from the material, as long as the author of the original work is cited properly. 